\title{
Longitudinal Versus Horizontal Uterine Incision of Intramural Myoma Regarding Complications in Abdominal Myomectomy
}

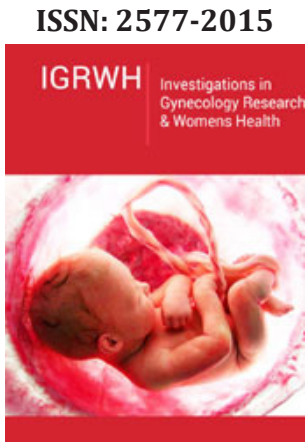

${ }^{*}$ Corresponding author: Randa Abobakr Abobakr, Faculty of Medicine, Egypt

Submission: 漈July 12, 2019

Published: 阱August 1, 2019

Volume 3 - Issue 2

How to cite this article: Alfatah $\mathrm{S} \mathrm{H}$ Hosny T, Randa A A. Longitudinal Versus Horizontal Uterine Incision of Intramural Myoma Regarding Complications in Abdominal Myomectomy. Invest Gynecol Res Women's Health.3(2). IGRWH.000556.2019.

DOI: 10.31031/IGRWH.2019.03.000556

Copyright@ Randa Abobakr Abobakr, This article is distributed under the terms of the Creative Commons Attribution 4.0 International License, which permits unrestricted use and redistribution provided that the original author and source are credited.

\author{
Alfatah Salem HA ${ }^{1}$, Hosny TA² and Randa Abobakr Abobakr ${ }^{3 *}$ \\ ${ }^{1}$ Professor of Obstetrics and Gynecology, Egypt \\ ${ }^{2}$ Assistant Professor of Obstetrics and Gynecology, Egypt \\ ${ }^{3}$ Faculty of Medicine, Egypt
}

\begin{abstract}
Objective: To compare between different uterine wall incision direction, vertical incision and transverse incision in abdominal myomectomy of intramural myoma regarding to complications.

Methods: The study were conducted on 60 patients attending the shatby University Maternity Hospital underwent abdominal myomectomy for a single site intramural myoma. They were randomly divided into vertical incision group ( 30 patient) and a transverse incision group (30 patient). The intra-operative blood loss, uterine wound size.
\end{abstract}

Results: We proved that there was no significant difference between both incision regarding intra-operative blood loss, uterine incision size.

Keywords: Intramural myoma; Abdominal myomectomy; Transverse incision; Longitudinal incision

\section{Introduction}

Uterine leiomyomas (fibroids) are the most common benign gynecologic tumors. They primarily affect women of reproductive age, and the estimated incidence of fibroids is over $70 \%$ by 50 years of age $[1,2]$. Most of women with uterine fibroids are asymptomatic. Abdominal pain, anemia and menorrhagia, dyspareunia can indicate the presence of fibroids [3]. Myomectomy is an operative choice for symptomatic women who desire future fertility. Blood loss during myomectomy has always been a field for investigation .it has been assumed that horizontal uterine incision causes more blood loss and more complications .Traditionally, vertical incisions has been popularized to decrease the risk of extending the uterine incision into the cornual, tubes, or broad ligament and vessels [4] on the other hand Morita et al. [5] who studied the difference between transverse and longitudinal uterine incision in laparoscopic myomectomy considered transverse incision a reasonable direction for incision of the uterine wall as transverse uterine incision avoids sectioning the arcuate vessels that branch off from the ascending uterine arteries and run transversely across the uterus [6]. In our study, we have performed abdominal myomectomies using vertical incisions parallel to the longitudinal axis of the uterus, and transverse incisions at a right angle to the longitudinal axis of the uterus and compared and studied the results of both types of incisions.

\section{Methods and Materials}

The study was conducted on 60 patients attending the shat by University Maternity Hospital. Premenopausal women underwent abdominal myomectomy for a single site myoma, for any reason, were eligible for inclusion. Patient with previous myomectomies, or previous uterine surgery were excluded in this study. The study population was divided into 2 equal groups, where patients were randomly assigned to one of the two techniques:

1. Group A: 30 patients who were planned for transverse uterine incision.

2. Group B: 30 patients who were planned for longitudinal uterine incision.

Our Primary outcome is to measure actual blood loss while operations as ABL=BV [Hct(i)Hct(f)]/Hct(m) Blood Volume=Body Wt in Kg x 70 $\mathrm{mlkg}^{-1} \mathrm{Hct}$ (i), Hct (f) and Hct (m): the initial, 
final and mean (of the initial and final) Hematocrits respectively. Blood volume Adults: $70 \mathrm{ml} / \mathrm{kg}$ body weight [7]. Size of uterine wound also were compared. preoperative and postoperative laboratory samples were done in the same laboratory. Same group of surgeons to avoid bias related to surgical skills. No patient had received hormonal therapy for myomas before the operation. The study was exposed to the hospital Ethics committee and a signed written informed consent was obtained from each patient.

\section{Operative technique}

Antibiotic prophylaxis was given as a single dose of intravenous $1^{\text {st }}$ generation cephalosporins (Cefazoline $($ ) 2 gm taken 30 to 60 minutes before skin incision [8]. myomectomies were performed under general anesthesia using a standardized anesthesia protocol in both groups. Patients were placed in supine position followed by urinary catheterization - after general anesthesia- surgical sterilization and toweling. Pfannenstiel incision was done. Group (A) patient myomectomies were performed via longitudinal uterine incision as the incision was made nearly central over the myoma. Blunt and sharp dissection to expose the stalk of the myoma with continuous coagulation of the surrounding myometrium. The uterine incision (incision 1) was measured using uterine sound (Figure 1). The remaining attachment of the Myoma is removed then closure of the myometrium in two layers with a continuous absorbable suture in order not to leave any space for accumulation of blood. Then, the uterine incision (incision 2) after closure the uterine myometrium was measured in $(\mathrm{cm})$ (Figure 2). The uterine serosa is sutured in a running (baseball) fashion, to minimize adhesion formation.

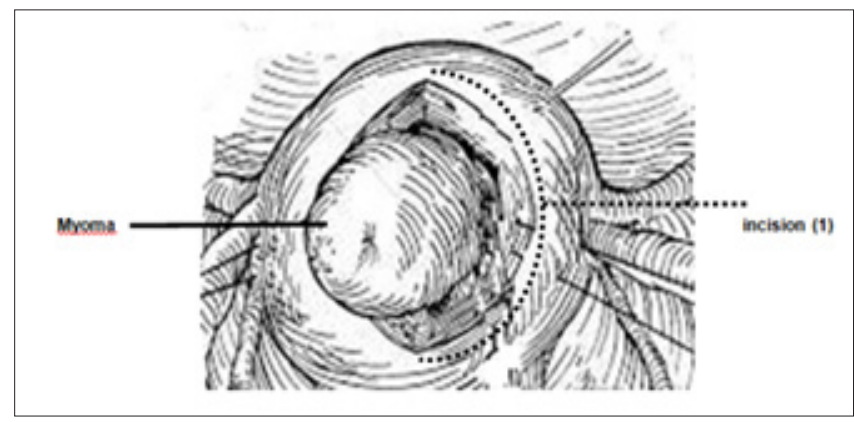

Figure 1: Measuring of incision (1).

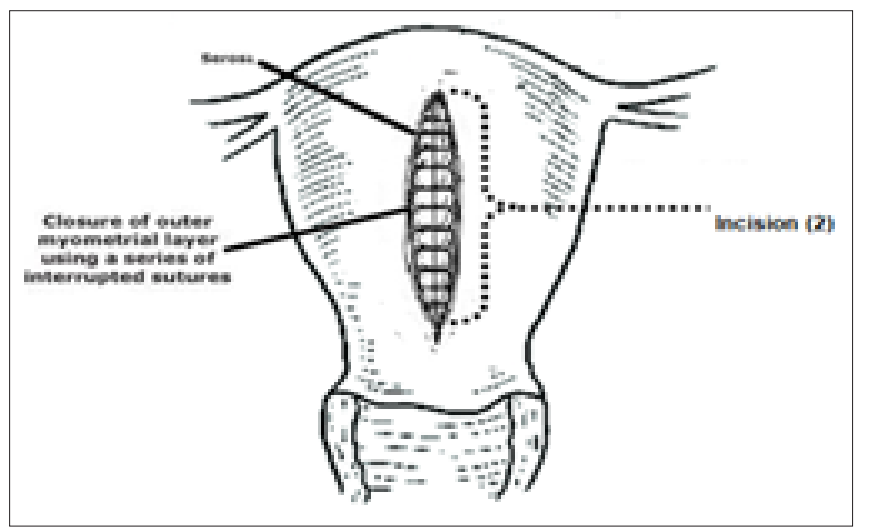

Figure 2: Measuring of incision (2).
Group (B) patient myomectomies were performed via transverse uterine incision in the false capsule. It ended well away from the tubal ostia. Blunt and sharp dissection to expose the stalk of the myoma with continuous coagulation of the surrounding myometrium. The uterine incision is measured using uterine sound. Myoma is removed then closure of the myometrium in two layers with a continuous absorbable suture then, uterine incision was measured using uterine sound (Figure 3). The uterine serosa is sutured in a running fashion (Figure 3): measuring of the uterine incision by uterine sound. Patients were observed postoperatively for vital signs and bowel motion. Oral intake was allowed after 24 hours and after checking bowel movement.

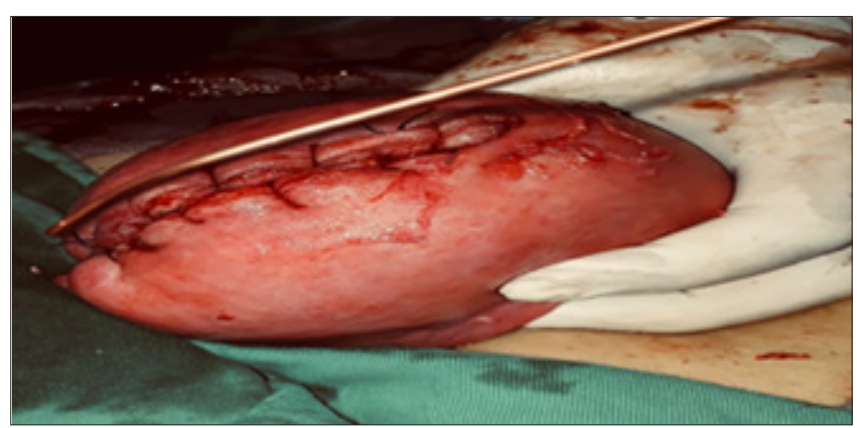

Figure 3: Measuring of the uterine incision by uterine sound.

\section{Statistical analysis of data}

Statistical analysis was carried out using SPSS statistics software version 23. Quantitative data were tested for normality using Kolmogorov-Smirnov test. The variables which normally distributed described by Mean $\pm S D$. the variables which not normally distributed, described by median (Min-Max). Qualitative data was expressed by numbers and percent. The used tests were

\section{Independent student's t test}

A. In Comparison between Vertical versus horizontal incision as regard Pre-suture incision \& Post-suture incision \& myoma size

B. In Comparison between Vertical versus horizontal incision as regard blood loss

Correlation test: To detect Relation between myoma size with Pre-suture incision \& Post-suture incision \& blood loss in vertical incision group and in horizontal incision group

\section{Result}

No statistically significant differences were seen between the two groups with respect to age, patient weight and body mass index. there is evidence of an inverse relationship between the incidence of fibroids and parity

There were no statistical significance differences between Vertical versus horizontal incision as regard length of incision (1) \& length of incision (2) as $\{(t=1.3, P=0.203),(t=0.477$, $\mathrm{P}=0.635$ ) respectively\}. As well there was no statistical significance 
differences between Vertical versus horizontal incision group as regard Myoma size, $(\mathrm{t}=0.442, \mathrm{P}=0.661)$.

There is highest significant positive correlation between myoma size with incision (1) \& (2) length and blood loss as ( $\mathrm{r}=$ $0.866, \mathrm{p}=.0001, \mathrm{r}=0.746, \mathrm{p}=.0001, \mathrm{r}=0.842, \mathrm{p}=.0001$ respectively ) regarding vertical incision, as well, There is highest significant positive correlation between myoma size with incision(1) \& (2) size, and blood loss as ( $\mathrm{r}=0.950, \mathrm{p}=.0001, \mathrm{r}=0.895, \mathrm{p}=.0001, \mathrm{r}=0.552$ , $\mathrm{p}=0.002$ respectively ) regarding to horizontal incision.

\section{Discussion}

Currently, many efforts focus on reducing blood loss during myomectomy, yet to our knowledge no studies investigated the difference between longitudinal and uterine incision in open myomectomy, however in the study conducted by Morita et al. [5], they were compared in laparoscopic myomectomy [5]. The sociodemographic characteristics of the patients are shown in Table 1. The mean age of the population was $30.27 \pm 5.698$ years ranged from 22 to 42 years. There is evidence of an inverse relationship between the incidence of fibroids and parity as shown in Table 2. Pregnancy is known to be protective against fibroids; ischaemia of the uterus during parturition and selective apoptosis of small lesions during postpartum uterine remodeling are possible explanations [9-11] also there is no statistical significance difference between Vertical versus horizontal incision group regarding to patient body weight and body mass index. As well, there was no statistical significance differences between Vertical versus horizontal incision group as regard Myoma size, $(\mathrm{t}=0.442, \mathrm{P}=0.661)$ with Mean $\pm \mathrm{SD}$ for vertical incision group $8.133 \pm 1.189$ while the Mean \pm SD for horizontal $7.967 \pm 1.691$
Table 1: Socio-demographic characteristics of Females study sample regarding age.

\begin{tabular}{|c|c|}
\hline Characteristics & Study Sample $(\mathrm{n}=60)$ \\
\hline Age (years) & \\
\hline Mean \pm SD & $30.27 \pm 5.698$ \\
\hline Range & $22-42$ \\
\hline
\end{tabular}

Table 2: Socio-demographic characteristics of Females study sample regarding parity.

\begin{tabular}{|c|c|c|}
\hline Characteristics & Frequency $(\mathrm{n}=60)$ & Percent \\
\hline Parity & & \\
\hline Nulipara & 23 & 38.3 \\
\hline Primpara & 16 & 26.7 \\
\hline Multipara & 21 & 35 \\
\hline
\end{tabular}

Previous studies Sawin et al. [11] showed that the average volume of blood loss during abdominal myomectomy (performed via laparotomy) is 200 to $800 \mathrm{~mL}$ [11]. Our study showed that the directly estimated intra-operative blood loss (using actual blood loss formula) was lower in the transverse uterine incision group compared to the longitudinal uterine incision group (528.00 $\pm 177.13 v s 532.33 \pm 118.865$ ); though this difference failed to reach statistical significance. The average blood loss through longitudinal incision is consistent with results obtained by other studies performing the same incision (Table 3). during the myomectomy operation is from 280 to $820 \mathrm{CC}$ Table 4.

Table 3: Socio-demographic characteristics of female's study sample regarding patient weight and BMI.

\begin{tabular}{|c|c|c|c|}
\hline & Vertical Incision $(\mathbf{n}=\mathbf{3 0})$ & Horizontal Incision $(\mathbf{n}=\mathbf{3 0})$ & Test of Significance $(\mathbf{p})$ \\
\hline Weight $(\mathrm{kg})$ & & & \\
\hline Mean \pm SD & $79.63 \pm 10.8$ & $79.9 \pm 11.15$ & $(\mathrm{t}=-.094, \mathrm{P}=.925)$ \\
\hline BMI $\left(\mathrm{kg} / \mathrm{m}^{2}\right)$ & & & \\
\hline Mean \pm SD & $31.97 \pm 4.68$ & $32.24 \pm 4.87$ & $(\mathrm{t}=-.212, \mathrm{P}=.83)$ \\
\hline
\end{tabular}

Table 4: Comparison between Vertical versus horizontal incision as regard length of incision (1) \& length of t; independent t test.

\begin{tabular}{|c|c|c|c|}
\hline & Vertical Incision (n=30) & Horizontal Incision (n=30) & Test of Significance (p) \\
\hline Incision (1) (cm) & & & \\
\hline Mean \pm SD & $7.363 \pm 1.133$ & $7.05 \pm 1.422$ & $(\mathrm{t}=1.3, \mathrm{P}=0.203)$ \\
\hline Incision (2) (cm) & & & $(\mathrm{t}=0.477, \mathrm{P}=0.635)$ \\
\hline Mean \pm SD & $6.59 \pm 1.165$ & & \\
\hline Myoma size (cm) & $8.133 \pm 1.189$ & $7.967 \pm 1.691$ & $(\mathrm{t}=0.442, \mathrm{P}=0.661)$ \\
\hline Mean \pm SD & & & \\
\hline
\end{tabular}


We found that, there is high significant positive correlation between myoma size and blood loss for both horizontal and vertical incision as ( $\mathrm{r}=0.552, \mathrm{p}=0.002, \mathrm{r}=0.842, \mathrm{p}=.0001$ respectively) as illustrated in Table 5;

Table 5: Relation between myoma size with Preoperative incision \& Post-operative incision\& blood loss.

\begin{tabular}{|c|c|c|c|c|c|}
\hline \multicolumn{6}{|c|}{ Some parameters } \\
\hline & & & $\begin{array}{c}\text { Preoperative } \\
\text { incision } \\
(\mathrm{cm}) \\
(\mathrm{N}=\mathbf{3 0})\end{array}$ & $\begin{array}{c}\text { Postoperative } \\
\text { incision } \\
(\mathrm{cm}) \\
(\mathrm{N}=30)\end{array}$ & $\begin{array}{c}\text { Blood loss } \\
(\mathrm{ml}) \\
(\mathrm{N}=30)\end{array}$ \\
\hline \multirow{4}{*}{ Myoma size } & \multirow{2}{*}{ Vertical incision } & Pearson Correlation (r) & 0.866 & 0.746 & 0.842 \\
\hline & & $\mathrm{p}$ & $0.0001^{*}$ & $0.0001^{*}$ & $0.0001^{*}$ \\
\hline & \multirow{2}{*}{ Horizontal incision } & Pearson Correlation (r) & 0.95 & 0.895 & 0.552 \\
\hline & & $\mathrm{p}$ & $0.0001^{*}$ & $0.0001^{*}$ & $0.002^{*}$ \\
\hline
\end{tabular}

Morita et al. [5]. Who studied the difference between transverse and longitudinal uterine incision in laparoscopic myomectomy on 50 women (each group was 25) showed that for the transverse incision group, the amount of bleeding $(137.6 \pm 88.1 \mathrm{~mL})$ was a significantly lower value than for the vertical incision group $(235.8 \pm 169.4 \mathrm{~mL})$. They explain that was due to transverse uterine incision avoids severing the arcuate vessels that branch off from the ascending uterine arteries and run transversely across the uterus. However, since fibroids distort the normal vascular architecture, it is not possible to entirely avoid severing vessels in the myometrium. Blood loss in this study was much lower than in our study which is expected due to pneumoperitoneum and use of electrocautery.

Iftikhar et al. [12] conducted on 50 patients with average sized single myoma via a single classical uterine incision, to show the outcome of abdominal myomectomy after performing abdominal myomectomy the average blood loss in this study was much higher than our study (1800-2500ml). Another study by Al Harazi et al. [13] was conducted to study Controlling of blood loss at open myomectomy by local Ergometrine injection. This was a prospective, case-control study carried out at AL-Thawra General Hospital, Sana'a, Yemen. it included 79 patients who had abdominal myomectomy for symptomatic myomas. They were randomly divided into 2 groups, either to receive 40 patients receive ergometrine, or 39 patients as a control. The average blood loss in the control group who underwent a classical abdominal myomectomy via a longitudinal uterine incision was $490.6 \pm 86.4 \mathrm{ml}$. Morita et al. [5] compared vertical uterine incision and transverse uterine incision in laparoscopic myomectomy .It found that there is no significant differences between the two groups regarding to the number of suture stitches .Mean number of stitches for vertical incision $(n=25)$ was $4.9 \pm 1.3$ and while mean number of stitches for horizontal $(\mathrm{n}=25)$ was $5.2 \pm 1.2$ and myoma. Traditionally, vertical incisions have been popularized to decrease the risk of extending the uterine incision into the cornual, tubes, or broad ligament and vessels. In our study, we compared between vertical and horizontal incision as regard incision (1) size (cm) before suturing the myometrium and uterine incision 2 size $(\mathrm{cm})$ after suturing the myometrium. For vertical uterine incision group mean incisions (1) was $7.363 \pm 1.133$ and for incisions (2) was $6.59 \pm 1.165$ while for horizontal uterine incision group mean incision (1) was $7.5 \pm 1.422$ and incision (2) mean $6.45 \pm 1.109$. These results clarify that there are no statistical significance differences between vertical and horizontal uterine incision. We found that, there is high significant positive correlation between myoma size and the size of both incisions for both horizontal and vertical incision as $(\mathrm{r}=0.950$, $\mathrm{p}=.0001, \mathrm{r}=0.895, \mathrm{p}=.0001, \mathrm{r}=0.866, \mathrm{p}=.0001, \mathrm{r}=0.746, \mathrm{p}=.0001$ respectively). As illustrated in Table 5.

\section{Conclusion}

Transverse Uterine incision doesn't cause more blood loss than vertical incision. There is no difference between both groups regarding to uterine incision size.

\section{References}

1. Cao M, Qian L, Zhang X, Suo X, Lu Q et al. (2017) Monitoring Leiomyoma response to Uterine Artery Embolization Using Diffusion and Perfusion Indices from Diffusion-Weighted Imaging. Biomed Res Int p. 3805073.

2. Lethaby A, Vollenhoven B (2015) Fibroids (uterine myomatosis, leiomyomas). BMJ Clin Evid.

3. Mendes RM, Vieira CS, Ferriani RA, Reis RM, Nogueira AA, et al. (2015) Presentation and treatment of uterine leiomyoma in adolescence: a systematic review. BMC Womens Health 15(1): 4.

4. Wallach, Myomectomy EE (1992) in: Thompson JD, Rock JA (Eds.), Te Linde's Operative Gynecology, $7^{\text {th }}$ edn, Lippincott-Raven, Philadelphia, USA, pp. 647-662.

5. Morita M, Asakawa Y, Uchiide I, Nakakuma M, Kubo H (2004) Surgery results using different uterine wall incision directions in laparoscopic myomectomy of the intramural myoma. Reprod Med Biol 3(1): 33-37.

6. Brown GF, Beilby JO, Tarbit MH (1970) The blood supply of the uterus. 1. Arterial vasculature. J Obstet Gynaecol Br Commonw 77(8): 673-681.

7. Schorn MN (2010) Measurement of blood loss: review of the literature. J Midwifery Womens Health 55(1): 20-27.

8. Classen DC, Evans RS, Pestotnik SL, Horn SD, Menlove RL, et al. (1992) The timing of prophylactic administration of antibiotics and the risk of surgical-wound infection. N Engl J Med 326(5): 281-286.

9. Baird DD, Dunson DB (2003) Why is parity protective for uterine fibroids? Epidemiology 14(2): 247-250.

10. Wise LA, Palmer JR, Harlow BL, Spiegelman D, Stewart EA, et al. (2004) Reproductive factors, hormonal contraception, and risk of uterine leiomyomata in African American women: a prospective study. Am J Epidemiol 159(2): 113-123. 
11. Sawin SW, Pilevsky ND, Berlin JA, Barnhart KT (2000) Comparability of perioperative morbidity between abdominal myomectomy and hysterectomy for women with uterine leiomyomas. Am J Obstet Gynecol 183(6): 1448-1455.

12. Iftikhar R (2009) Outcome of abdominal myomectomy. J of Surgery Pakistan 14(2): 85-88.
13. Kaima A, Abdelrahman H, Al Harazi (2016) Controlling blood loss at open myomectomy by local Ergometrine injection: interventional study. Sudan Med J 52(2): 61-66.

For possible submissions Click below: 